\title{
A REFLECTIVE LEARNING APPROACH TO TEACHING COMPUTER AND INFORMATION TECHNOLOGY COURSES
}

\author{
Ping Wang, Robert Morris University, wangp@rmu.edu
}

\begin{abstract}
The field of computer and information technology has been and will be among the fast growing career options, and college education remains a primary path for preparing the future workforce for this field. The need to innovate and improve the effectiveness of teaching and learning in computer and information technology courses continues to be of research and practical significance. This study proposes a reflective learning model of teaching and learning activities to encourage and promote students' self-reflection and self-assessment in computer and information technology classes. An experimental instrument for reflective learning was used in different classes at a U.S. university. The data gathered during a period of three years indicate strong correlations between students' reflective learning and their academic progress and achievements. This study presents the proposed model, reflective learning instrument, data collections, and discussions of the findings.
\end{abstract}

Keywords: Computer and information technology, reflection, reflective learning, self-assessment, outcomes

\section{INTRODUCTION}

The field of computer and information technology continues to be one of the fast-growing areas for professional employment. The latest occupational outlook data from the U.S. Bureau of Labor Statistics (BLS) show that computer and information technology occupations are projected to add over half a million new jobs or grow 12 percent from 2018 to 2028, which is much faster and with better pay than the average for all occupations (US Labor Department BLS, 2020). The occupational data also indicate that an overwhelming majority of the occupations in computer and information technology require an entry-level education of a bachelor's degree in the field. The growing workforce demand for computer and information technology professionals brings increasing opportunities for institutions of higher education to educate and prepare graduates for the occupations in this field.

However, it is also a challenging task for universities and colleges to prepare qualified graduates with necessary skills to fill the technical positions as survey studies have shown a disconnect between industry and education in computer and information technology and a technology skills gap between dynamic job expectations and potential and current employees (CompTIA, 2020; Schirf \& Serapiglia, 2017). ABET CAC (Computing Accreditation Commission) has been an established global professional organization to review and accredit computing and information technology programs for program quality assurance. ABET CAC provides up-to-date program criteria that include studentlearning outcomes and documented assessment for continuous improvement (ABET CAC, 2018). Thus, research on innovation and continuous improvement in the teaching and learning methods and activities is of theoretical and practical significance to the quality and outcomes of computer and information technology education.

Self-examination or self-reflection has been commonly recognized as an important method of teaching and learning in traditional Confucianism and modern educational research (Chang, 2019; Gibbs, 1988; Haller \& Gapp, 2007; Stefano, Pisano, Gino, \& Staats, 2016; Tan, 2020). Reflection is closely related to experiential learning involving individual hands-on experience and a form of indirect assessment of learning outcomes from the learner's perspective. However, there has been little research on the role of reflective learning in teaching and learning of computer and information technology, which includes individual hands-on learner experience as an important component in learning. Therefore, this study is to focus on the role of reflection in teaching computer and information technology courses. The goal of this research is to contribute a new model of reflective learning with a specific instrument for selfassessment to improve the effectiveness of teaching and learning in the field of computer and information technology. The proposed model will be illustrated with empirical data from different college level computer and information 
technology classes at a U.S. university. The following sections will review the theoretical background, illustrate, and explain the proposed reflective learning model, describe the research method and instrument used for data collection, and discuss the findings and conclusions.

\section{BACKGROUND}

This study defines reflection as a high-level deep learning process of articulating, assessing, and internalizing acquired knowledge and experience. Reflective learning develops a learner's skills, abilities and wisdom in critical thinking and problem solving that will benefit future performance. Prior research by Stefano, Pisano, Gino, and Staats (2016) highlights deliberate articulation and codification of past experience in defining the reflective learning experience and addressing the question of which learning source provides the highest benefits to future performance in organizational behavior. The results from their multiple lab experiments and field studies indicate that reflection of acquired experience is superior to accumulation of additional experience in terms of benefiting future performance.

The value of reflective learning has been deeply rooted and emphasized in the traditional Confucianist philosophical approach to education. Confucius (551-479 BC), the ancient Chinese philosopher and master educator, made the following statement on the highest level learning of wisdom: "By three methods we may learn wisdom: First by reflection which is the noblest; second by imitation, which is the easiest; and third by experience, which is the bitterest”(Atkinson, 2016, p.46). Confucianism advocates deep learning for deep understanding and wisdom versus surface or shallow learning. Confucian heritage emphasizes reflective thinking over knowledge and experience as an essential and integral component of the learning process, and it is found that the reflective learning approach by Confucian heritage students leads to deep learning outcomes challenging the belief about their mechanical "rote learning” style (Haller, Fisher, \& Gapp, 2007).

Reflective teaching is necessary for reaching the goal of reflective learning in Confucian philosophy. In Confucianism, reflective learning is a constant and endless process for knowledge of wisdom and ethical virtues, and both teachers and students are required to reflect on their teaching and learning in order to expand their knowledge on the subjects of teaching and learning and their understanding of the world (Zhao, 2013). Research among teachers guided by traditional Confucian philosophy approach to education and reflection shows that new knowledge is discovered through constant reflection of the teaching experience, which benefits the learning of students (Huang \& Vong, 2016). In addition, research with textual analysis on the masterpieces of Confucian education theory such as Xueji and Analects shows that reflective teaching and learning from the Confucian perspective values critical and creative thinking through questions and answers, deep discussions and formulating one's own conclusions (Tan, 2020).

Kolb's Experiential Learning Theory (ELT) incorporates reflection in learning but only as a part of the reflective observation stage in the experiential learning cycle (Kolb, 1984). ELT centers on knowledge discovery through experience. Kolb's experiential learning cycle, as shown in Figure 1 below, consists of the following 4 stages:

(1) Concrete Experience (CE): To be involved and experience in a task or assignment

(2) Reflective Observation (RO): To take time to think, review and reflect on what has been experienced

(3) Abstract Conceptualization (AC): To interpret and draw conclusions to understand the experience

(4) Active Experimentation (AE): To try out learning and apply it to practice 


\section{Issues in Information Systems}

Volume 21, Issue 2, pp. 19-29, 2020

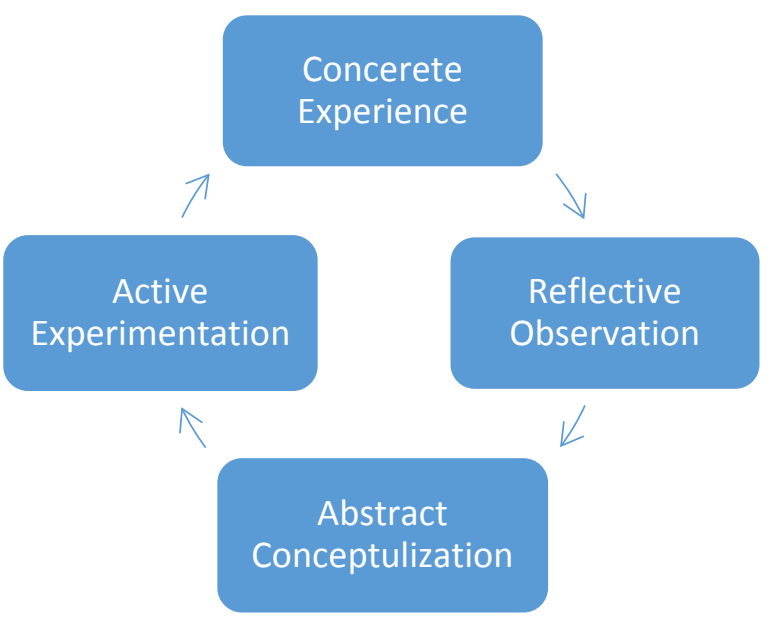

Figure 1. Kolb’s Experiential Learning Cycle (1984)

Gibbs expands reflection to the entire learning process and develops a reflective cycle of learning in which learners reflect systematically on different stages of learning activities and experience. Figure 2 below illustrates the Gibbs reflective cycle of learning.

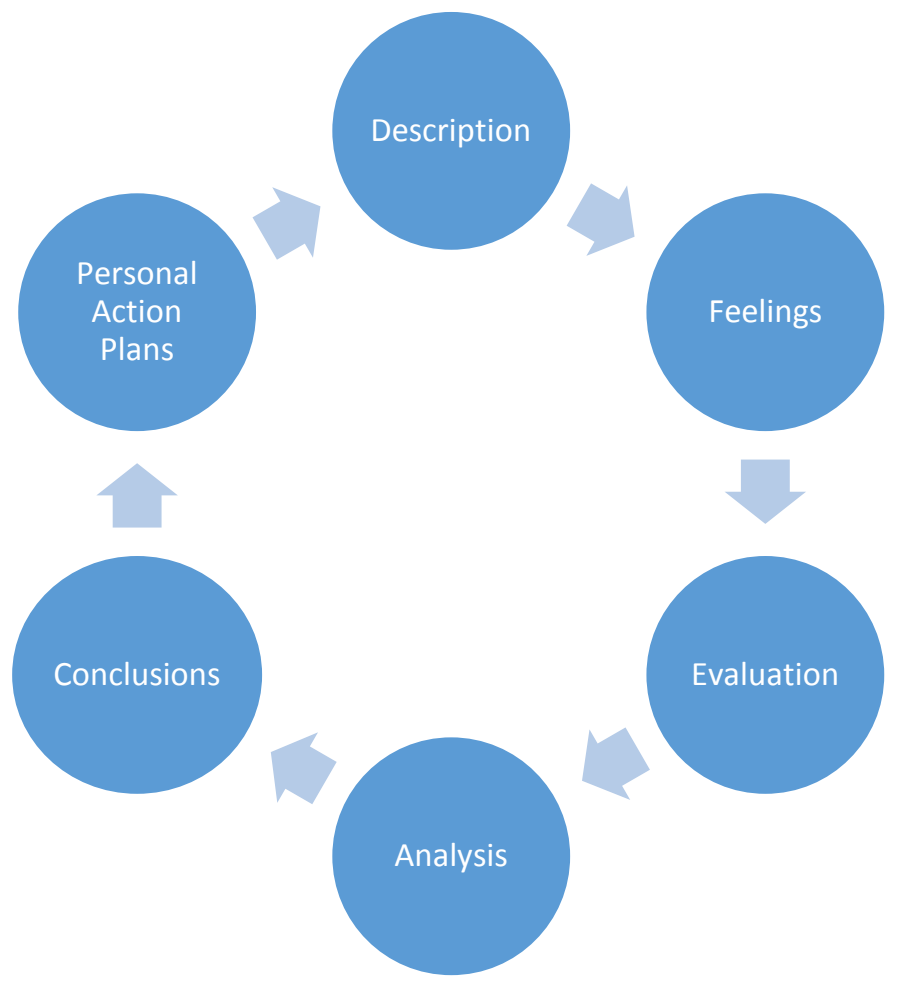

Figure 2. Reflective Learning Cycle (Gibbs, 1988)

The Gibbs Reflective Learning Cycle consists of the following six components:

1. Description: Recall and describe what happened in the learning activity or experience

2. Feelings: Identify learner's feelings and reactions to the experience

3. Evaluation: Make value judgements about the pros and cons of the experience

4. Analysis: Bring outside experience and research to help understand the situation

5. Conclusions: Draw conclusions on what has been learned from the experience and analysis 
6. Personal Action Plans: What steps to take next time based on what has been learned

Self-assessment is embedded in the Gibbs Reflective Learning Cycle as an important method for judging and validating the learning outcomes. According to Gibbs, the individual learner's self-assessment should include both the beginning direct experience and the ending conclusions in the reflective process and should be taken seriously as part of the formal assessment system. "While comments and appraisal from the trainer or peers may be valuable, ultimately it is the individual's self-assessment which matters” (Gibbs, 1988, p.51).

Reflection and self-assessment are found to be closely inter-related in the learning process and help students to develop more responsibility and independence in planning, monitoring, and evaluating their academic work (Phillips, 2016). A comprehensive survey of research on the practices of student self-assessment (SSA) shows improved student motivation and performance in learning, but further research is needed in the future to determine the accuracy of the self-assessment against teacher/curricular expectations as well as the impact of expert feedback on student performance (Panadero, Brown, \& Strijbos, 2016). The study by Wium and Plessis (2016) uses a reflective journal assessment tool for medical students at service-learning sites with results showing positive changes among the students in their analytical and critical thinking, emotive aspects, social responsibility, and self-confidence. However, the study also identifies the need for regular feedback and guidance on the reflective process from the instructor or supervisor to improve the student's reflective practices and self-assessment (Wium \& Plessis, 2016). Student reflection should not an isolated activity, as external feedback is likely to make student reflection and self-assessment of learning more accurate (Soemantri, Mccoll, \& Dodds, 2018).

Extensive empirical studies have identified positive effects of reflection on learning, especially inexperience-based learning. Reflective journal writing helps to develop critical thinking, self-evaluation, and innovation as a student of education and a clinical instructor (Tsang, 2009). Reflective learning in experiential service learning improves students' job-readiness and employability as well as their high-level critical reflection and thinking skills (Bennett, Power, Thomson, Mason, \& Bartleet, 2016). Reflection in midwifery clinical practice improves professional readiness, critical thinking, decision-making, and professional fulfillment of the practitioners (Wain, 2017). Reflective learning is especially applicable and essential to effective learning in medical education due to many unstructured learning activities and variability and complexity of clinical cases (Soemantri, Mccoll, \& Dodds, 2018). Reflection in learning also applies to online learning. A recent study among students in online courses in education using reflective learning assignments finds that reflection brings multiple pedagogical and educational benefits, such as increasing students' knowledge depth, identifying insufficient areas for improvement, personalizing and contextualizing knowledge, and helping learners to build structural connections in knowledge and social connections among learners (Chang, 2019).

However, prior research on reflective learning has been primarily in the fields of teacher education, medical education, and organizational behavior. There has been very little research on reflective learning in computer and information technology education even though this is a field that involves diverse learning activities including the important component of hands-on experiential learning for professional readiness. Therefore, this study is to focus on this significant area to contribute a proposed model, instrument, and empirical data.

\section{PROPOSED MODEL}

This study proposes a new model of reflective learning for computer and information technology education. Figure 3 below shows the proposed model. 


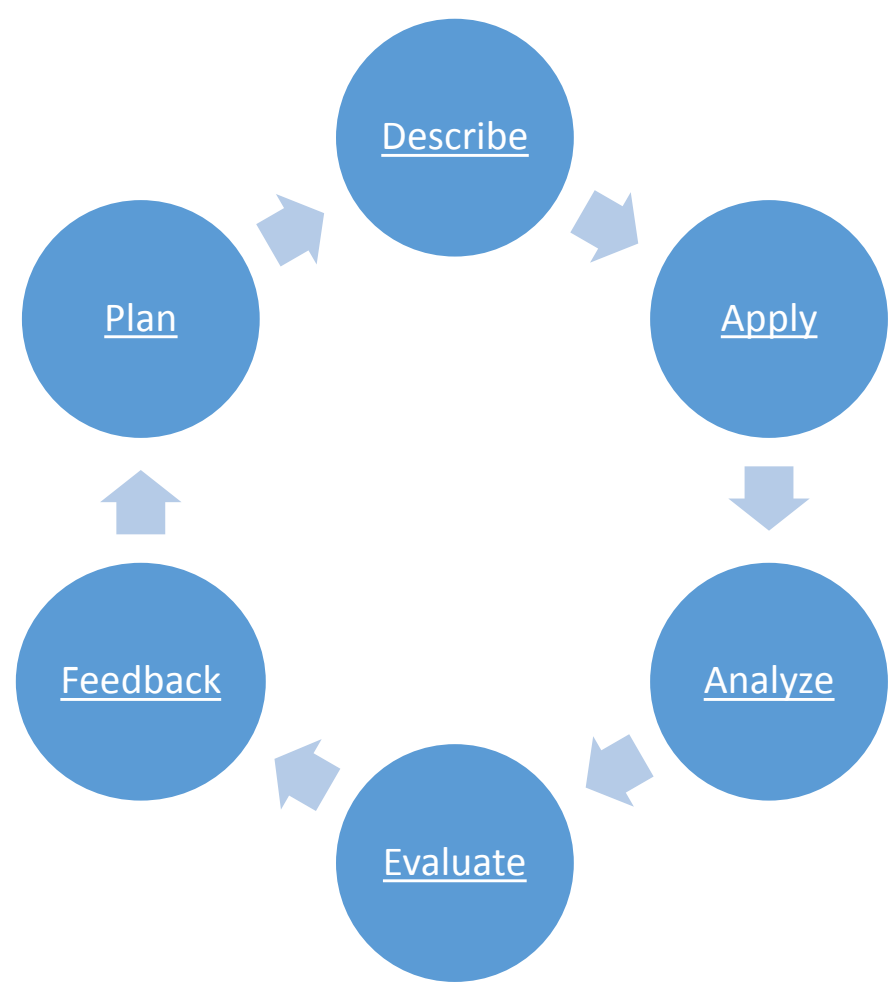

Figure 3. Proposed Model of Reflective Learning

The proposed model of reflective learning for computer and information technology education draws upon the theoretical background reviewed above including the experiential learning theory and the Gibbs reflective learning cycle. The proposal also takes into consideration the student learning outcomes for computing majors as well as the Bloom's taxonomy levels for cognitive learning.

The reflective learning process in computer and information technology education should support the achievement of student learning outcomes. ABET CAC publishes the up-to-date program criteria and student outcomes for global computing program accreditation. The following are the current (2019-20) common student outcomes or knowledge, skills and abilities expected for students in the programs of Computer Science, Information Systems, and Information Technology (ABET CAC, 2018, p.3):

1. Analyze a complex computing problem and to apply principles of computing and other relevant disciplines to identify solutions.

2. Design, implement, and evaluate a computing-based solution to meet a given set of computing requirements in the context of the program's discipline.

3. Communicate effectively in a variety of professional contexts.

4. Recognize professional responsibilities and make informed judgments in computing practice based on legal and ethical principles.

5. Function effectively as a member or leader of a team engaged in activities appropriate to the program's discipline.

The reflective learning process in computer and information technology education is also a cognitive development process that goes through different levels or stages of learning objectives. The updated Bloom's taxonomy lays out 6 
levels of progressive learning objectives with specific action verbs for each level of achievement (Anderson \& Krathwohl, 2001):

1. Remembering: Recall information, facts, terms, and basic concepts

2. Understanding: Demonstrate comprehension of facts and ideas through descriptions and interpretations

3. Applying: Solve problems in new situations by applying knowledge and techniques learned

4. Analyzing: Examine information to identify causes, motives, and relationships

5. Evaluating: Make judgement about information or ideas based on certain criteria

6. Creating: Propose new or alternative solutions

To serve the student outcomes for computer and information technology and incorporate the Bloom's taxonomy levels of learning, the proposed Model of Reflective Learning in Figure 3 above consists of the following six components in a progressive process of learning and assessment:

1. Describe: This is for the learner to describe, explain, and demonstrate knowledge and understanding of important information, facts, and basic concepts and principles learned on a certain topic.

2. Apply: This is for the learner to use learned knowledge, skills, and techniques to solve problems in a new situation, which is also expected in Student Outcome 1 from ABET CAC.

3. Analyze: This is for the learner to examine the relationships and draw conclusions on complex computer problems, which is expected in Student Outcome 1 from ABET CAC.

4. Evaluate: This is for the learner to assess the pros and cons of computing-based solutions learned or experienced with to make judgments or recommendations on the quality and validity of the solutions. This is expected in Student Outcome 2 from ABET CAC.

5. Feedback: This is an interactive step for the learner to receive feedback and guidance from the instructor on the reflection to validate or adjust student self-assessment and improve the effectiveness of reflective learning.

6. Plan: This is for the learner to create or design new or alternative solutions for problem solving based on the reflective learning experience.

\section{METHODOLOGY}

The proposed Model of Reflective Learning for this study was used in four different undergraduate computer and information technology courses at a regionally accredited private non-profit university in northeastern United States. The four courses that used this model were: network technology \& management, network/data communication, IT security \& assurance, and computer network security. The data used for this research was collected among 6 groups during 3 years (or 6 semesters) from spring 2017 to fall 2019. The Daily Review \& Assessment Form in Figure 4 below is a sample of the instrument used for the experiment and data collection. 


\section{Daily Review and Assessment Form}

Today is: 02/20/2019|1:45pm

*** Please save all graded daily review forms as proof of class attendance and participation ***

Name Course: $\underline{\text { INFS } 3235}$

1. Please briefly summarize or list the topics covered and hands-on lab/practice done in to day's class:

2. What important or useful knowledge and/or skills did you learn from to day's class?

3. Questions of the day:

1) What is spear phishing? What type of vulnerability does it exploit?

2) What would be the best solution to defend against spear phishing?

4. Do you still have any questions or needs regarding today's class? Yes ; No

If yes, please specify:

Late Arrival: No ; Yes $(@$ j; Early Departure No ; Yes $(@$

Thank you for your feedback! Look forward to seeing you again next class.

*Remember: You are always welcome to my office hours for help (see syllabus for my office hours)

Figure 4. Daily Review and Assessment Form

The design of the Daily Review and Assessment Form instrument fits the needs of the proposed Model of Reflective Learning. The instrument not only measures but also guides and facilitates the student reflective learning process on a regular and daily basis. Question 1 in the form asks students to summarize and recap the conceptual topics and hands-on experience. Question 2 implies that students should understand the concepts and skill areas covered in the class. Question 3 part 1 explicitly checks students' understanding of the key concept of the day. Question 4 explicitly asks if each student has any questions or needs related to the topics of the day. Questions 1, 2, 3, and 4 together enable 
students to recall, reflect on and demonstrate their comprehension of the important concepts and hands-on experience, which measures the Describe component of the proposed reflective learning model. At this stage, the students can also self-assess and see how much they did know and understand and what they still do not know or understand.

The instrument addresses the Apply component of the proposed reflective learning model in Questions 1 and 2. Question one askes the students to recall and recap any hands-on work where they were supposed to use knowledge, skills and tools for problem solving. Question 2 asks students to interpret and compare the value and significance of any hands-on work from their perspectives.

Question 2 and Question 3 in the instrument also address the Analyze component of the reflective learning model for this study. To answer Question 2, the students must examine the concepts and hands-on experience, relate them to the learning objectives of the day, and weigh and compare the value and usefulness of each topic and hands-on work item. To answer Question 3, the student must examine possible security vulnerabilities and solutions against the spear phishing threat to analyze and make any connections.

Question 2 and Question 3 part 2 in the instrument explicitly ask the student for evaluation, which addresses the higher-level Evaluate component of the reflective learning model. In Question two, the student needs to make judgement on the value and usefulness of each concept or practical work item. In Question 3 part 2, the student needs to compare and evaluate all possible solutions to make a judgement or recommendation on the best solution.

The Daily Review and Assessment form satisfies the Feedback component of the reflective learning model. The form was created, designed, and distributed by the instructor to begin each daily reflection and self-assessment. The instructor collects the completed forms from students at the end of each class meeting to review, provide feedback, and give a pass/fail grade based on participation and completion. The instructor returns the graded forms to students at the following class meeting and asks students to review the feedback and save the graded forms as evidence of attendance and participation. The interactive feedback helps students to validate, reinforce, adjust, and improve their reflection and self-assessment of their learning experience. External feedback is likely to improve accuracy of student reflection and self-assessment of learning (Soemantri, Mccoll, \& Dodds, 2018).

Finally, the daily review instrument not only encourages students' critical thinking but also motivates them toward questioning, probing and creative thinking. This feature addresses the Plan component of the reflective learning model. Question 3 part 2 encourages students to come up with the best solution to the spear phishing problem with no predefined answers or restrictions given, which allows students to explore creative ideas and designs. Question 4 encourages students to ask any questions, including creative thoughts and plans.

\section{FINDINGS AND DISCUSSIONS}

The study on reflective learning using the Daily Review and Assessment Form instrument above was conducted among undergraduate students in some computer and information technology classes from spring 2017 to fall 2019, not including summer. The instrument was distributed to each student near the end of each class allowing the student about 15 to 30 minutes to reflect and complete. Each daily form completed by the student was collected, reviewed, and graded as pass or fail by the instructor with written feedback and then returned to the student in the following class. The daily review work item was required of every student except for the control group. Any student who missed or failed four or more of the daily reviews would receive a failing grade for this assessment item. The Daily Review and Assessment Form was designed to help students improve their learning and succeed in the course work as the reflective learning process should help students improve their performance on the course assignments, projects, and exams. Table 1 below presents the aggregate findings of the study during the 3-year period. 
Table 1. Aggregate Data on Daily Review \& Assessment Study Groups

\begin{tabular}{|l|c|c|c|}
\hline Semester & Participants (N) & Reflection Pass Rate & Course Success Rate \\
\hline Spring 2017 & 37 & $95 \%$ & $88.70 \%$ \\
\hline Fall 2017 & 46 & $91 \%$ & $86.40 \%$ \\
\hline Spring 2018 & 43 & $93 \%$ & $90.20 \%$ \\
\hline Fall 2018 & 21 & $100 \%$ & $96.80 \%$ \\
\hline Spring 2019 & 23 & $96 \%$ & $93.50 \%$ \\
\hline Fall 2019 & 26 & $98 \%$ & $92.60 \%$ \\
\hline & Total N $=\mathbf{2 1 6}$ & Average $=\mathbf{9 5 . 5 0 \%}$ & Average $=\mathbf{9 1 . 3 7 \%}$ \\
\hline
\end{tabular}

Table 1 presents the number of Participants (N), Reflection Pass Rate, and Course Success Rate by semester. The data points are aggregates, as individual performance record is not shown here. The number of Participants $(\mathrm{N})$ is the number of undergraduate students who participated in the daily review and assessment process for reflective learning. The total number of student participants for the 3-year period is 216. The demographic attributes of the students represent typical college student enrollment with no substantial age or gender gap. The Reflection Pass Rate is the percentage of student participants who successfully completed and passed the daily review and assessment process based on the instructor's review, grading, and feedback. The Course Success Rate is the average weighted percentage score of the participating student group for the semester. The weighted score ranges from $0 \%$ as the lowest to $100 \%$ as the highest and includes grades from all assignments, projects, and exams.

The findings in Table 1 indicate that the overwhelming majority of the students in each group completed the reflective learning process successfully through the daily review and self-assessment activities. The average successful completion rate of all six groups is $95.50 \%$. The successful reflection appears to be consistent with the students' success in the overall course work as the average course success rate of the six groups is $91.73 \%$, which is also high. This study used Microsoft Excel to calculate the Pearson correlation coefficient $r$-value between the Reflection Pass Rate and the Course Success Rate. The correlation coefficient $r$-value result is 0.91 and indicates a strong correlation between students' regular reflective learning and their success in the overall course work.

In addition, this study used a control group of 18 students in a class for fall 2018 where the daily review and assessment instrument was not used for data collection. The aggregate findings from the control group are shown in Table 2 below.

Table 2. Aggregate Data on the Control Group

\begin{tabular}{|l|c|c|c|}
\hline Semester & Participants (N) & Reflection Pass Rate & Course Success Rate \\
\hline Fall 2018 & 18 & NA & $83.72 \%$ \\
\hline
\end{tabular}

The 18 students in the control group were given an alternative assignment instead of the Daily Review and Assessment form. Thus, their reflection pass rate is NA (not applicable). Their average course work success rate is $83.72 \%$, which is substantially lower than the average of $91.73 \%$ for the 6 groups that participated in the required reflective learning 
process using the daily review and assessment instrument. This difference in the performance does suggest the possible positive effect of regular reflective learning on course work achievement.

\section{CONCLUSION}

This research proposes a reflective learning model for teaching undergraduate computer and information technology courses. The new model incorporates Confucianist philosophical approach to education, prior research on experiential learning and reflective learning, the revised Bloom's taxonomy on levels of learning, and ABET CAC student outcomes for computing education. The model consists of the progressive components and steps of Describe, Apply, Analyze, Evaluate, Feedback, and Plan for students to learn from continuous reflection and self-assessment to improve their knowledge, comprehension, analytical skills, critical thinking, problem solving, and abilities to make sound judgement and create new solutions. To illustrate the proposed reflective learning model, this study uses an innovative Daily Review and Assessment Form instrument for the experiment of a routine reflective learning activity among 6 groups of undergraduate students during a 3-year period. A separate group of students who did not receive this reflective learning instrument was used as the control group. The results from the experiment indicate a significant correlation between the rate of successful completion of the reflective learning process and the overall student success rate in the course work. In addition, the average student success rate among the 6 groups receiving the reflective learning treatment is significantly higher than that of the control group without the reflective learning treatment.

The findings of this study suggest that a significant and positive relationship exists between a reflective learning process with interactive guidance and feedback from the instructor and student academic performance and success rate in computer and information technology courses. A practical implication is that a well-designed reflective model and instrument with instructor involvement as used in this study may help to create a positive and conducive learning environment for students to improve in knowledge, technical skills, critical thinking, and creative problem solving. This study also suggests that student self-assessment with guidance and feedback from the instructor may be considered as an effective and valuable part of regular assessment of student learning for continuous improvement. This study is only a preliminary research effort on the role of reflective learning in computer and information technology education. The current study is limited to the correlation between the reflection activity and the overall course success rate based on aggregate data. Future studies may focus on individual student performance and include additional variables such as different courses and expectations and students' academic and technical background. Further research into the role of the instructor in the reflective learning process may be promising as well.

\section{REFERENCES}

ABET CAC (Computing Accreditation Commission). (2018). Criteria for Accrediting Computing Programs (20192020). Retrieved from https://www.abet.org/

Anderson, L.W., \& Krathwohl, D.R. (2001). A taxonomy for learning, teaching, and assessing, Abridged Edition. Boston: MA: Allyn and Bacon.

Atkinson, H. (2016). The beginnings of wisdom: Challenges in engineering education. Engineering, 2(2016), 45-47.

Bennett, D., Power, A., Thomson, C., Mason, B., \& Bartleet, B. (2016). Reflection for learning, learning for reflection: Developing indigenous competencies in higher education. Journal of University Teaching \& Learning Practice, 13(2016:2), 1-19.

Chang, B. (2019). Reflection in learning. Online Learning, 23(1), 95-110. doi:10.24059/olj.v23i1.1447

CompTIA. (2020). Workforce and Learning Trends 2020. Retrieved from https://www.comptia.org/content/research/it-workforce-learning-trends-analysis

Gibbs, G. (1988). Learning by doing: A guide to teaching and learning methods. Oxford, UK: Oxford Polytechnic. 
Haller, C., Fisher, R., \& Gapp, R.P. (2007). Reflection as a means of understanding: ways in which Confucian Heritage students learn and understand organisational behaviour. Multicultural Education \& Technology Journal, April 2007, 6-24. DOI: 10.1108/17504970710745175

Huang, H., \& Vong, S.K. (2016). The Confucian educational philosophy and experienced teachers' resistance: A narrative study in Macau. Front. Educ. China 2016, 11(1), 1-22. DOI 10. 3868/s110-005-016-0001-7

Kolb, D. A. (1984). Experiential learning: Experience as the source of learning and development. New Jersey: Prentice-Hall.

Panadero, E., Brown,G.T.L., \& Strijbos, J. (2016). The future of student self-assessment: A review of known unknowns and potential directions. Educ Psychol Rev (2016) 28. 803-830. DOI: $10.1007 / \mathrm{s} 10648-015-9350-2$

Phillips, J.A. (2016). Student self-assessment and reflection in a learner controlled environment. Retrieved from https://arxiv.org/abs/1608.00313v1

Schirf, E., \& Serapiglia, A. (2017). Identifying the real technology skills gap: A qualitative look across disciplines. Information Systems Education Journal (ISEDJ), 15(6), 72-82.

Soemantri,D., Mccoll, G., \& Dodds, A. (2018). Measuring medical students' reflection on their learning: Modification and validation of the motivated strategies for learning questionnaire (MSLQ). BMC Medical Education, 18(1):274. doi: 10.1186/s12909-018-1384-y

Stefano, D.S., Pisano, G.P., Gino, F., \& Staats,B.R. (2016). Making experience count: The role of reflection in individual learning. Harvard Business School Working Paper 14-093, 1-36.

Tan, C. (2017). Confucianism and education. Oxford Research Encyclopedia, Education, 1-16.

Tsang, A. (2009). Reflective learning as a student and an educator: Connecting the scholarship of teaching and learning. International Journal for the Scholarship of Teaching and Learning, 3(2), 1-4.

US Labor Department BLS (Bureau of Labor Statistics). (2020, April). Retrieved from https://www.bls.gov/ooh/computer-and-information-technology/home.htm

Wain, A. (2017). Learning through reflection. British Journal of Midwifery, 25(10), 662-666.

Wium,A., \& Plessis, S. (2016). The usefulness of a tool to assess reflection in a service-learning experience. AJHPE, 8(2),178-183.

Zhao, J. (2013). Confucius as a critical educator: Towards educational thoughts of Confucius. Front. Educ. China 2013, 8(1): 9-27. DOI 10.3868/s110-002-013-0003-9 